\title{
Histological and Clinicopathological Studies Following Partial Hepatectomy in Dogs
}

\author{
Osama A. Abdalla, ${ }^{*}$ Mohamed A. Awad,, ${ }^{* *}$ Seham A. Helmy, ${ }^{* * *}$ and \\ Mohamed T.Abdou* \\ Depts. of Clinicalpathology*, Surgery, Anesthesiology \& Radiology** and Cytology \& \\ Histology ${ }^{* * *}$ Faculty of Veterinary Medicine, Suez Canal University.
}

\begin{abstract}
This study was carried out to evaluate the state of the liver in dogs after partial hepatectomy by histopathological and clinicpathological examinatons. Fifteen healthy male dogs were used in this study and classified into equal three groups. Dogs of group (I) served as control and exposed to laparotomy, dogs of group (II) were used for partial hepatectomy of left lateral lobe while those of group (III) were subjected to partial hepatectomy of the whole left lobe. Blood samples were taken at $1^{\text {st }}$, $2^{\text {nd }}, 3^{\text {rd }}, 4^{\text {th }}, 6^{\text {th }}$ and $8^{\text {th }}$ weeks of surgery to determine: alanine aminotransferase aspartate aminotransferase, alkaline phosphatase and glucose. After the $8^{\text {th }}$ weeks, the dogs were sacrificed to obtain the liver for the histopathological and histochemical examinations. Group (I) showed normal liver structure. Group (II, III) showed signs of regeneration where hypertrophy of the hepatocytes and increase number of binucleated cells were evident. The hepatocytes nuclei were at different stages of nuclear activities. There were newly formed bile duct. The glycogen level in the liver decreased after
\end{abstract} J. Vet. Anat. resection. The intensity of the reaction to acid phosphatase, alkaline phosphatase, ATPase and SDH increased after resection. In conclusion, after partial hepatectomy the hepatic tissue try restore its original size through regeneration of the hepatocytes.

\section{Key words}

Histopathology, clinicpathology, heaptictomy, dog.

\section{Introduction}

Hepatic resection or partial heaptectomy is indicated in many conditions such as traumatic fracture of hepatic parenchyma (Kirk and Bistner, 1975), hepatic abscessation (Martin,1981). Primary or secondary tumors of hepatic and biliary ducts (Drazner, 1985) and in cases of liver hydatid cyst (Singh, 1987). Hepatic lobectomy is carried out nowadays to obtain a liver graft (Drazner, 1985).

Certain experimental hepatectomies were done following induced surgical conditions such as ischaemic remnant 
lobes or obstructive jaundice to study the extent of liver dysfunction, comparing hepatectomy with normal circulation or normal biliary drainage (Mizumoto, Kawarado, Yomiawaki, Noguchi and Nishido, 1979). Experimental partial hepatectomy was carried out to investigate its postoperative complications, especially liver dysfunction, not only the functional reserve but also the regeneration capability (EIGuindi and Mottelib, 1974).

There was rapid increase in both size of the liver cells (hypertrophy) and active cell division and multiplication (hyperplasia) following $80-90 \%$ of hepatic resection in man, rodents, pigs, frogs and birds (Albert, et al., 1979). Moreover, the remnant liver mass increased remarkably and reached to the original mass at 2 weeks after $70 \%$ partial hepatectomy in dogs (Ichikawa et al., 1984).

The regenerative response is influenced by the amount of the liver removed at operation, with the maximum response occurring after $70 \%$ partial hepatectomy. The compensatory hypertrophy which is the enlargement of the regenerating hepatocytes is more evident in $70 \%$ than in $40 \%$ partial hepatectomy Starzel et al., (1987).

The aim of the present study is to evaluate the state of the dogs liver after partial hepatectomy by histopathological and clinicopathological means.

\section{Materials and Methods}

The present study was performed on 15 clinically healthy male mongrel dogs with age $1-2$ years and body weight of $15-20 \mathrm{~kg} / \mathrm{dog}$. The experiment extended 8 weeks after the hepatectomy. The dogs were classified into three groups each group consists of five dogs as the following.

- Group (I) used as control and exposed to laparo-tomy only.

- Group (II) subjected to partial hepatectomy of left lateral lobe.

- Group (III) subjected to partial hepatectomy of left lateral lobe and left central lobe (whole left lobe).

\section{1- Biochemical examination}

Blood samples were taken after the operation and during the experiment at $1^{\text {st }}, 2^{\text {nd }}, 3^{\text {rd }}, 4^{\text {th }}, 6^{\text {th }}$ and $8^{\text {th }}$ weeks from groups I, II and III. Blood collected to determine serum enzymatic activities and glucose

\section{2- Statistical analysis of the data}

The obtained data were analyzed using Statistical Package for Social Science (SPSS version 16.0). The mean of results, the standard deviation and the standard error were also calculated according to Kalton (1967).

\section{2-Histopathological examination:}

After the $8^{\text {th }}$ week the dogs of all groups were sacrificed to obtain the liver for the histopathological examination, which collected immediately and fixed in $10 \%$ neutral buffered formaline and Bouin's solution. The specimens were 
dehydrated in ascending grades of alcohol, cleared in xylene and embedded in paraffin wax. $3-5 \mu \mathrm{m}$ thick, sections were obtained and subjected to:

1- Harris's Haematoxylin and Eosin (H\&E) for general histological examination.

2- Periodic-Acid Schiffs (PAS) reaction for detection of glycogen and neutral mucopolysaccharides.

3- Best's carmine reaction for detection of glycogen.

4- Heidenhain's iron haematoxylin stain for the detection of mitotic figures. This stain used to calculate the mitotic index (MI) by dividing the number of cells had mitotic figures in the liver onto the total number of cells. The calculation included the average of 3-4 different fields $X 1000$ magnification.

$(\mathrm{MI})=$ number of the dividing cells $/$ total number of the cells) $\times 100$.

caves and Ergene-Gozukara (2003).

In group (I) (MI): $\{16 / 30+17 / 28+25 / 42$ $=58 / 100=58 \%\}$

In group (II) (MI): $\{20 / 38+32 / 40+15 / 22$ $=67 / 100=67 \%\}$

In group (III) (MI): $\{19 / 30+28 / 30+35 / 40$ $=82 / 100=82 \%\}$

\section{3- Enzyme histochemistry:}

The liver specimens were rapidly taken and immersed in liquid nitrogen ($\left.196{ }^{\prime} \mathrm{C}\right)$, sectioned at $\left(-20^{\prime} \mathrm{C}\right)$ in cryostat

J. Vet. Anat. where 10 um thick sections were obtained for histochemical investigation as:

1- Calcium cobalt method for demonstration of alkaline phosphatase.

2- Gomori's lead method for detection the localization of acid phosphates.

3- Nitro-blue tetrazolium (NBT) method for demonstration of Succinic dehydrogenase.

4- Modified method for detection of ATPase (Adenosine-triphosphatase).

The histological and histochemical procedures were followed as outlined by, Drury and Wallington (1980) and Bancroft, Stevens and Turner (1990).

\section{Results}

\section{1- Biochemical finding:}

\section{1- $A L T$}

In this result the ALT activity in the serum was increased in group (II \& III) than in group (I), its increase was highly significant between $\mathrm{G} 1, \mathrm{G} 2$ and $\mathrm{G} 3$ in $1^{\text {st }} \mathrm{w}, 2^{\text {nd }} \mathrm{w}, 3^{\text {rd }} \mathrm{w}$ and $6^{\text {th }}$ weeks, but the same groups showed non significant increase in the $8^{\text {th }}$ week. At the $4^{\text {th }}$ week there were highly significant increase between $\mathrm{G} 1$ \& $\mathrm{G} 2$ and $\mathrm{G} 1$ \& $\mathrm{G} 3$ and non significant increase between $\mathrm{G} 2$ \& G3 (Table 1).

\section{2- AST}

The AST activity in the serum increased in group (II \& III) than in group (I), with highly significant increase between G1, 
G2 and G3 in $1^{\text {st }} w, 2^{\text {nd }} w, 3^{\text {rd }} w$ and $4^{\text {th }}$ weeks, but the same groups showed non significant increase in the $8^{\text {th }}$ week. In the $6^{\text {th }}$ week there were highly significant increase between G1 \& G2 and G1 \& G3 and non significant increase between G2 \& G3 (Table 1).

\section{3- Alk. Ph.}

The Alk. Ph. activity increased in the serum in group (II \& III) than in group (I), with highly significant increase between $\mathrm{G} 1, \mathrm{G} 2$ and $\mathrm{G} 3$ in $1^{\text {st }} \mathrm{w}, 2^{\text {nd }} \mathrm{w}$, $3^{\text {rd }} \mathrm{W}, 4^{\text {th }} \mathrm{W}$ and $6^{\text {th }}$ weeks. But at the $8^{\text {th }}$ week there was significant decrease between $\mathrm{G} 1$ \& $\mathrm{G} 2$ and $\mathrm{G} 2$ \& $\mathrm{G} 3$ and non significant decrease between $\mathrm{G} 1$ \& G3 (Table 1).

\section{4- Glucose}

The glucose level in the serum was decreased in group (II \& III) than in group (I) but along the duration of the experiment the level of the glucose increased. Its decrease was highly significant between G1, G2 and G3 at $1^{\text {st }} w$, and $6^{\text {th }}$ weeks. At $2^{\text {nd }} w, 3^{\text {rd }} w$ and $4^{\text {th }}$ weeks there were highly significant decrease between (G1 \& G2) and (G1 \& G3) and non significant decrease between G2 \& G3. In the $8^{\text {th }}$ week there was non significant decrease between the three groups. (Table 1).

\section{2- Histopathological findings:}

\section{Macroscopically:}

All groups of dogs (G1, G2 \&G3) were sacrificed two months postoperation and showed adhesions between the parietal and the visceral surfaces of the liver and the adjacent organs particularly

J. Vet. Anat. the diaphragm stomach and the intestine. Dogs subjected to partial hepatectomy of the left lateral lobe (group II) showed enlarged liver with normal color and consistency without any other macroscopic changes. Liver of dogs subject-ted to partial hepatectomy of the left lateral and left central lobes (group III) showed pale color with normal consistency and enlargement of the remaining liver mass which reached nearly to the normal liver size.

\section{Microscopically: \\ Group (I)}

The hepatocyte within the hepatic cord showed normal appearance, with the same size, and the normal average range of the hepatocyte diameter was about $11 \mu \mathrm{m}$ (Fig. 1). The cytoplasm was pale eosinophilic and symmetrically in the staining affinity to the majority of the hepatocytes. The nuclei were euchromatic and lightly basophilic. The central vein was of normal appearance. The hepatic sinusoids were normal and unremarkable (Fig. 2A). The portal area (bile duct, hepatic artery and the portal vein) showed normal appearance with few cellular infiltration (Fig. 2B).

\section{Group (II)}

The microscopic examination revealed hypertrophy of the liver as a result of hepatocytes enlargement with increased size of the cytoplasm and the nuclei (Figs. 3A\&4), in which the average range the cell diameter was $17.6 \mu \mathrm{m}$ (in group II) (Fig. 5). Also, the hepatocytes taken different shape and different staining affinity of their cytoplasm. Vaccuolation could be also seen within the hepatocyte (Figs 4\&6).

Vol 2 No1, (2009) 17 - 34 
The nuclei were enlarged in its size; large numbers of hepatocytes were binucleated (Figs. 3A\&B). The chromatin materials within the nuclei distributed in a different way where some were of dispersed chromatin within the nucleus or arranged on the inner surface of the nuclear envelope. (Figs 7A\& 8A).

The central vein showed swelling and thickening in its wall as a result of edema or partial hyalinization, some times the central vein contained hemolyzed RBCs and thrombosis could also be detected (Fig. 9).

Some hepatic sinusoids were dilated (Fig. 3B), others were congested (Fig. 4), There were also newly formed blood sinusoids and blood capillaries. The Kupffer's cells increased in number and showed moderate hypertrophy (Fig. 3A\&B).

The portal area showed different changes including: newly formed bile duct with immature hepatic artery and portal vein (Figs. 7B\&10B). Enlargement of the bile duct was evident as a result of mild hyperplasia or hypertrophy in its epithelial lining (Fig. 11). Edema in the portal area was seen (Figs. 10B\&11), with congestion of the hepatic artery (Fig. 10B). Prolife-ration of the fibroblast and angioblast (Figs. 10A-11) was noticed in the portal area and result in formation of newly formed blood capillary (Fig. 11).

\section{Group (III)}

The signs of regeneration in the liver of this group were pronounced, in which the hepatocytes were hypertrophied and reached $18.9 \mu \mathrm{m}$ in size (Fig. 12). Large numbers of the hepatocytes were binucleated (Fig. 13A). The nuclei were enlarged in its size and showed stages of nuclear division (Fig. 8B). Swelling and thickening in the central vein were evident. The hepatic sinusoids were swollen (Fig. 13B) and others congested. The Kupffer's showed hyper-trophy and hyperplasia than that present in group (II) (Fig. 13A,B). Their were also newly formed blood sinusoids and blood capillaries. There were newly formed portal area. Swelling of the bile duct was seen as a result of sever hypertrophy and hyperplasia in its epithelial lining (Fig.14). The portal area showed edema, congestion and prolife-ration of the fibroblasts and angioblasts.

The hepatocytes showed intensive positive reaction to Periodic Acid Schiffs (PAS) and Best's carmine in group (I) (Fig. 15A\&B), the reaction became moderate in group (II) and faint in group (III) (Figs. 16A\&B and 17A\&B).

The mitotic index was $58 \%$ in group (I) (Fig. 18), 67\% in group (II) and $82 \%$ in group (III) (Fig. 8A\&B).

\section{3- Histochemichal finding:}

The hepatocytes in group (I) showed moderate reaction to acid phosphatase (Fig. 19A), alkaline phosphatase (Fig. 19B), ATPase (Fig. 20A) and SDH (Fig. 20B), the reaction become increased in its density in group (II) (Fig. 21A, 22A, 23A, 24A) and showed 
intensive reaction in group (III) (Fig. 21B, 22B, 23B, 24B). The alkaline phosphatase concentrated in the liver tissue especially in the sinusoidal and bile canalicular surface of the liver, but the ATPase concentrated around the central veins and the blood vessels.

\section{Discussion}

\section{Biochemichal finding:}

\section{Transaminases activity:}

The ALT activity is an indica-tor to hepatocyte necrosis or increased cell membrane permeability, while AST activity is not specific for liver dysfunction as other tissues contain enough AST such as skeletal and cardiac muscles, when they are dam-aged it will give rise an increased in the AST activity (Kaneko, 1973). Moreover Coles (1980) considered that ALT enzyme is called liver specific enzyme in dog, cat and primate only as it is present in large amounts in liver tissue and elevates with the liver diseases.

In the present study, increased activity of the ALT and AST in the serum was highly significantly different between G1, G2 and G3 in $1^{\text {st }} w, 2^{\text {nd }} w$, $3^{\text {rd }} \mathrm{W}$ and $4^{\text {th }}$ weeks, but the same groups showed non significant difference in the $8^{\text {th }}$ week. This result nearly similar to that of Mahmoud (2003) whom evaluated the degree of liver damage after its surgical interference depending on AST and ALT enzymes, the two enzyme activities showed marked elevation just post operation.
J. Vet. Anat.
The results are in agreement with findings of Mochinga (1981) that showed great and early increase in both enzyme activity values. Our results disagreed with the result reported by El-Amrousi et al. (1971) who found that the activity of both enzymes regained their normal values within 15 days in dogs after $30 \%$ partial heaptectomy. On the same time, Cohen et al. (1984) found that elevation of ALT and AST activities returned to their normal values 15 days after $40 \%$ and $70 \%$ partial hepatectomy in dogs.

\section{Alkaline phosphatase.}

Elevation of Alk. Ph. activity in the serum considered the best indication for the hepatic dysfunction. These results coincide with those of Coles (1980). Saint and Saint (1978) who mentioned that the elevated serum activity of Alk. $\mathrm{Ph}$. was indicated in certain hepatic dysfunctions specially in case of partial hepatectomy, single ligation of hepatic duct and/or obstructive jaundice.

In this investigation a highly significant increase in serum Alk. Ph. activity was observed in group (II \& III) than in group (I), this result agree with that of Mahmoud (2003) whom mentioned that cholecystilobectomy must give rise in the Alk. Ph activity than partial hepatictomy due to acute extrahepatic biliary obstruction associated with elevation in the activity of serum Alk.
Vol 2 No1, (2009) 17 - 34 
Ph. While Rutgers, Stradley and Johnson (1988) added that, this elevation may be due to alteration in the metabolism of bile acids and solubilization of the membrane of hepatocytes.

\section{Glucose:}

The glucose level in the serum was decreased with highly significant difference between G1, G2 and G3 in $1^{\text {st }} \mathrm{W}$, and $6^{\text {th }}$ weeks. In $2^{\text {nd }} \mathrm{w}, 3^{\text {rd }} \mathrm{W}$ and $4^{\text {th }}$ weeks there were highly significant difference between (G1 \& G2) and (G1 \& G3) and non significant different between G2 \& G3. At the $8^{\text {th }}$ week there was non significant different between the three groups. Similar results of partial hepatectomy were obtained by Nasser et al. (1993) and Mahmoud (2003).

\section{Histopathological and Histoch-michal finding}

After partial hepatectomy, the remaining liver increased in bulk. This adaptation of the liver tissue was not true regeneration, in which the replacement did not occur at the stump from which the lobe was removed but occurred by hypertrophy of the remaining lobes. This result agrees with Lopukhin (1976) who mentioned that, the process which is termed liver regeneration means accurately liver restoration or liver restitution.

The histopathological results revealed that dogs, particularly those sacrificed after the operation by 8 weeks showed some complications as adhesions of the liver to the J. Vet. Anat. adjacent organs and the liver become pale color in group (III), these result agree with $\mathrm{Abdel}$ Hafeez (1992) in dog and Aida (1996) in rabbit whom added that there were also abscess formation at the site of resection. Similar findings reported by many authors as Mcintyre et al. (1991) who reported necrosis, fistula and sepsis as complications of partial hepatectomy due to inadequate treatment. Aberti et. al., (1979) added that after partial hepatectomy in the rat, the remnant tissue become pale due to fatty change.

All the changes which were detected in the liver indicate signs of regeneration like, hyper-trophy of the hepatocyte and the nuclei take different shape that indicate these nuclei at different stages of nuclear division and the mitotic index which increased from group I to groups II and III, this result agree with Valdoni et al., (1957), Vajrabukka et al., (1975) and Alberti et. al., (1979) in man and dogs Taub (1996) confirmed that, following 80 to $90 \%$ liver resection of human, there was rapid increase in size of the liver cells (hypertrophy).

Also there were increase in the number of binucleated cells this result agreed with Mahmoud (2003) who confirmed that after partial hepatictomy of the left lateral lobe and the whole left lobe in dogs there were increase in the number of binucleated cells. But Aida (1996) said that after $50 \%$ hepatic resection in rabbit there were increase in the mitotic activity of the hepatocytes as 
the nuclei were large, vesicular and some cells showed double nuclei.

The vaccuolation that appeared within the hepatic cells could be due to the hypoxia that resulted from the regeneration of the hepatic cells that required more oxygen and nutrition more than the available amount so mild degeneration in the hepatic cells appeared in the form of vacuolar degeneration.

The hepatic sinusoids showed enlargement, congestion and other newly formed blood sinusoids, which were common with the early stages of the hypertrophy in the hepatocyte. Also these extension in the circulation for the production of enough blood supply to the newly formed area resulted from the regeneration, this result agreed with Aida (1996) after $50 \%$ and $70 \%$ hepatic resection in rabbit and Mahmoud (2003) after partial hepatictomy of the left medial lobe in dogs.

In this study there were hyper-trophy and hyperplasia of the Kupffer's cells, this result agreed with Alberti et. al., (1979) in, man, rodents, dogs and pigs and Aida (1996) after 25\%, $50 \%$ and $70 \%$ hepatic resection in rabbit.

In the present investigation there was newly formed portal area, hyperplasia in the epithelial lining of the bile ducts this result agreed with Aida (1996) after $70 \%$ hepatic resection in rabbit. The acid phosphatase is a lysosomal enzyme concerning with

J. Vet. Anat. the digestion of foreign substances and with anta-gonism of any bacteria, hence, it has an autolytic activity (Eidaroos, 1988) and (Seham 2004). Frank and Cistern (1986) suggested that, acid phosphatase enzyme is important for autoxidation of the unsaturated cell lipids derived from droplets or membranes of cell organelles that undergo lysosomal digestion. So this function of the acid phosphatase explain why the liver showed weak reaction to acid phosphatase in group (I) and the reaction became increased in its density in group (II) then in group (III), for digestion the remnant of the hepatic tissue after resection.

Martin (1976) mentioned that, the alkaline phosphatase is necessary for hydrolysis of glucose esters to release free glucose in the circulating blood, Deane (1947) emphasized that, alkaline phosphatase represents intermediaries in the metabolism of carbohydrates, lipid and proteins. Vacca (1985) found that, the alkaline phosphatase function is to breakdown phosphate esters by hydrolysis therefore it is involved in the process of energy release. The alkaline phosphatase concentrated in the liver tissue especially in the sinusoidal and bile canalicular surface of the liver this result agreed with Jacques (2007). So in this study the intensity of the reaction to the alkaline phosphatase increased in group (II) and reach the maximum in group (III), to hydrolysis the glucose esters and release free glucose in the circulating blood, this result confirmed with the reaction of the hepatocytes to PAS and

$$
\text { Vol } 2 \text { No1, (2009) } 17 \text { - } 34
$$


Best's carmine which give intense reaction in group (I), then moderate reaction in group (II) and faint in group (III), which indicate that, the level of the glycogen decreased in the liver to produce energy for regeneration and release free glucose in the circulating blood leading to hyper-glycemia.

Concerning the $\mathrm{SDH}$ as a mito-chondrial enzyme, its increase in activity denotes the view to a high metabolic activity of the cells (Hoyda, 2004). In this study the intensity of the reaction to the SDH increased in group (II) and reached the maximum in group (III), indicating increase in the hepatocyte activity.

The ATPase is a specific alkaline phosphatase enzyme and plays a role in the oxidative phosphorylation (Miraglia, Siqucira, Gorini and Priatos, 1975) and one of its important properties is hydrolytic ability of ATP (Pearse, 1977). In the present study, there were increase in the intensity of the reaction to the ATPase in group (II) and reach the maximum in group (III), this represent a response from the hepatic tissue to accommodate the energy required for regeneration.

From the aforementioned results we concluded that, the liver regeneration occurred in the remaining healthy liver within 8 weeks post hepatictomy by hypertrophy of the hepatocyte with newly formed portal area and blood capillary.

\section{References}

Abdel-Hafeez,M.M. (1992):

Partial hepatictomy and cholecystilobectomy in dogs. Assuit Vet. Med. J, 28 (56) 309 .

Aida, A. E. (1996):

Clinicopathologic studies on some surgical interference in rabbits. Ph.D., Fac. of Vet. Med., Zagazig Univ.

Albert, K. G.; K. M.

Stephen and G.H. Sadler (1979): Liver and Biliary Disease W. B. Saunders Company Ltd. London, Philadelphia, Toronto.

Bancroft, J. D.; Stevens and D. R. Turner (1990): Theory and practice of histologycal technique. $3^{\text {rd }} \mathrm{ed}$, Edinburgh London, Melbourne and New York.

Cavas, T. and S. Ergene Gozukara(2003): Micro-nuclei, nuclear lesions and interphase silver-stained nucleolar organizer regions (AG NOBS) as cytogenotoxicity indicators in oreochromis niloticus exposed to textile mill effluetmutat. Res.; 538 (1-2): 81-91.

Cohen,D.M.;J.B.Jaspan; K. S. Polonsky; E. G. Lever and A.R. Moossa, (1984): Pancreatic hormone profiles and metabolism posthepatectomy in the 
dog. Gastroenterology, 87: 679-687.

Coles, E.H. (1980):

Veterinary Clinical Pathology. $3^{r d} E d, W . B$. Saunders Comp.,Philadelphia, London.

Deane, H. W. (1947):

A cytochsmical survey of phosphateses in mammalian liver, pancreas and salivary glands. Am. J. Anat., $80-321$.

Drazner, (1985): General small animal surgery. In Gourley,I.M. and Vassear, P.R., Lippicott Company Philadelphia London, Mexico City, New York, Sydney.

Drury, R. A. B. and E. A.

Wallington (1980):

Carleton's histological technique, $5^{\text {th }}$ ed. Oxford, New York, Toronto, Oxford University Press

Eidaroos, H. (1988):

Comparative Histological and Histochemical Studies on the Abomasum of Some Ruminant Animals. PH. D., Fac. of Vet. Med., Zagazig Univ.

El-Amrousi, S.; M. El-Guindi; M. El-Monzaly and A. Mottelib (1971):Experimental studies on partial hepatectomy in dogs-.1.Surgical procedures and alteration in serum transaminases. U.A.R. J. Vet. Sci., 8 (I): 17-24.

El-Guindi, $M$. $H$. and $A$. A. Mottelib (1974): The effect of partial hepatictomy on some blood constituents in dogs. Assiut Vet. Med.. J. Vol. I, No. 1 \& $2: 139-145$.

Frank, A.L. and A.K. Cistern (1986):The localization of acid phosphatase in lipofuchsin granules and possible autophagic vacuoles in the interstitial cells of the guinea pig testes.J. Cell Biol., 36: 1.

Hoyda, A. S. K. (2004):

Histopathological and histochemical studies on the effect of the nonsteroidal anti-inflammatory drug "celebrex" on the liver and kidney of albino rat. M. D., of Science in Zoology. Suez Canal University.

Ichikawa, H.;K.Yamanako; T. Tobe and R. Mizumoto (1984): Bile secretion in regenerating liver a comparison of hepatic resection and ligation of the portal vein branch in dogs. Gastroenterol. Jpn. Aug., 19 (4): 320-327.

Jacques W. (2007):

Inerpretation of diagnostic tests. $8^{\text {th }} \mathrm{Ed}$. London Philadelphia and New York.

Kalton, G. (1967): Introduction of statistical ideas from Social Scientist. 2nd Ed. 5.

Kaneko, J.J. (1973): 
Standard values in domestic animals. $3^{\text {rd }} \mathrm{Ed}$. Department of Clinical Pathology, University of California, Davis.

Kirk, R.W. and S. L. Bistner (1975): Hand Book of Veterinary Procedures and Emergency Treatment. 2nd Ed. W.B. Saunders Company, Philadelphia,London, Toronto. Lopukhin, Yu. M. (1976):

Experimental Surgery. 1st Ed. Mir Publishers, Moscow.

Mahmoud H. E. (2003):

Surgical evaluation of the liver functions post partial hepatictomy in dogs. $\mathrm{PH}$. D., Fac. of Vet. Med., Alex. Univ.

Martin, B. L. (1976):

Alkaline phosphatase activity in some mammals. J. Anat., 85, 140-146.

Martin, E. C. (1981):

Percutaneous drainage in the management of hepatic abscess.Sur. Clin. North Am. 61 (I): 157 169.

Mcintyre, N.; J. P. Benha-mou; J. Bircher; M. Rizzetto and J.Rodes, (1991): Text Book of Clinical Hepatology, Vol.2.Oxford, New York, Tokyo.

Miraglia, T.;L. A. Siqucira; Gorini and G. Priatos (1975):Histochemical data on the liver of the marmoset, (callithrix jacchus). Acta. Anat., 91:57 cited by Eidaroos (1988).

Mizumoto, R.; Y. Kawarado; T.Yomiawaki;T.Noguchi and S. Nishido (1979): Resectability and functional reserve of the liver with obstructive jaundice in dogs. Am. J. of Surg. 10:302-310 .

Mochinga, N. (1981): Lipid metabolism in partially heaptectomized dogs and effect of hepatic peritoneal neurectomy. Jpn. J. Surg., 11(2): 115-123.

Nasser M.T.C.; M.A. Ali; A.S. Saleh and M.M. AbdelHafeez (1993): Liver restoration following partial heaptectomy and cholecystectomy in dog. Assiut Vet. Med. J., 29 (57):

Pearse, A. G. E. (1977):

Histochemistry, Theoretical and Applied $\left(3^{\text {rd } E d . ~}\right.$ Vol.l) Churchill. London.

Rutgers, H.C.; R.P. Stradley and S.E. Johnson (1988): Serum bile acid analysis in dogs with experimentally induced cholestatic jaundice. Amer. J. Vet. Res., 45(3): 121-128.

Saini, P.K. and S.K. Saini (1978): Origin of serum alkaline phosphatase in the dog. Amer. J. Vet. Res., 39: 151,E-1513.

Seham, A. H. (2004): 
Histological and histochemical studies on the gastrointestinal mucosa of the ostrich (Struthio camelus). PH. D., Fac. of Vet. Med., Suze Canal Univ.

Singh, H. (1987):

Hepatectomy simplified with the use of water scalpel. Indian J. Gastroenterology, Vol. 6 No. 3: 151-152.

Starzel, T. E.;A.

Francavilla and C. G. Halgrimson (1987): The origin, hormonal nature and action of hepatotropic substances in portal vein blood surgical. Gynecol. Obstet., 137: 179-199.

Vacca, L. L. (1985):

Laboratory mannual of histochemistry. Roven Press, New York.

Vajrabukka, T.; A. Bloon; M. Sussman; C. B. Wood and L. H. Blumgart (1975): Post-operative problems and management after hepatic resection for blunt injury to the liver. Br. J. Surg. 62: 189-200.

Valdoni, P.; M. Messini; G.

Ricci and $M$. Mancuso (1957): La Resezione Epatica Quale Impulso Rigeneratiro Nello terapia Dello-Cirrosis. Epatologia, 3: 1 

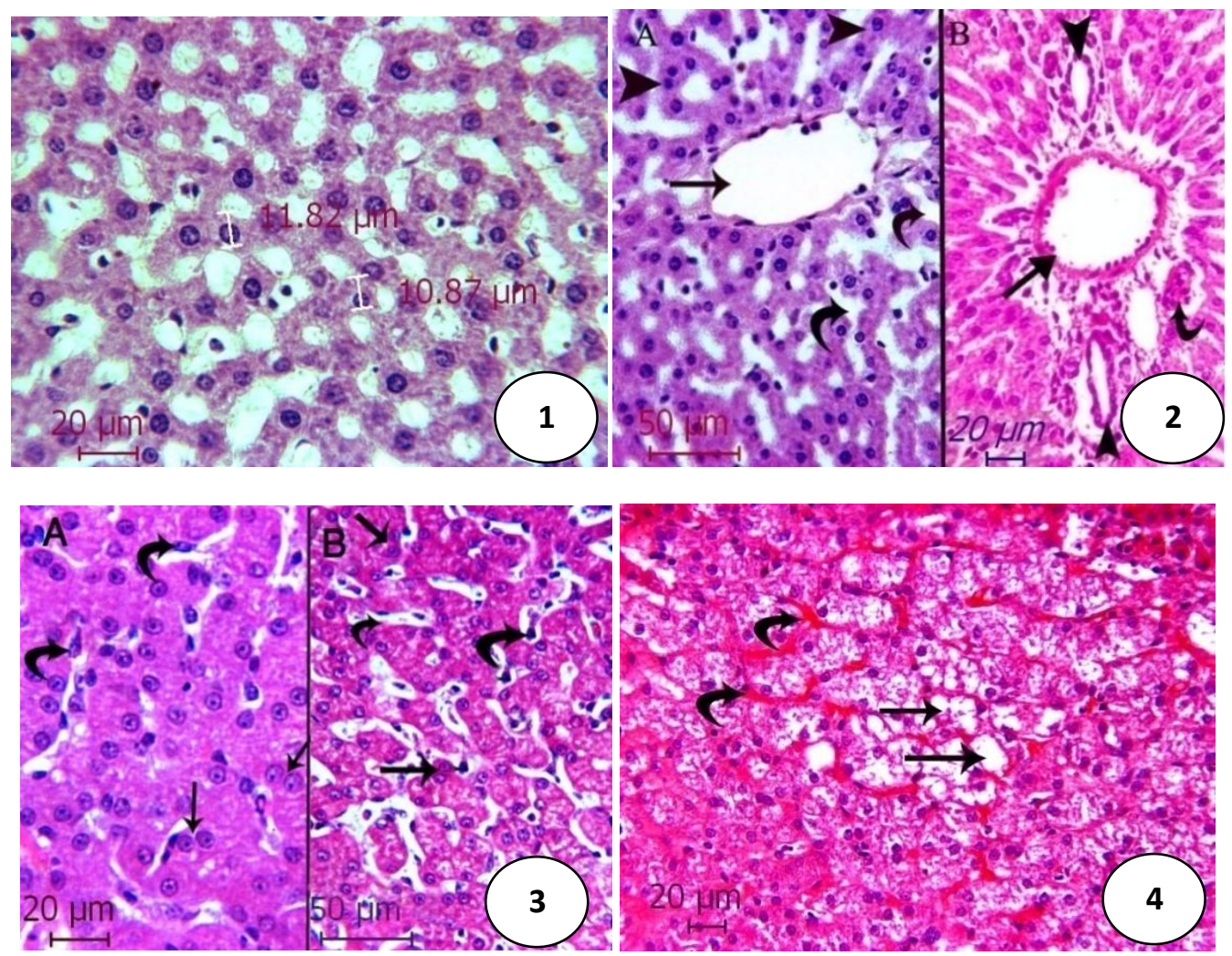

Fig (1): Group (I), a photomicrograph of dog liver showing the average normal size of the hepatocyte. Stain: H\&E.

Fig (2): Group (I), a photomicrograph of dog liver showing normal structure of: Ahepatocytes (head arrow), blood sinusoid (curved arrow) and the central vein (straight arrow). B- normal bile duct (head arrow), hepatic artery (straight arrow) and portal vein (curved arrow). Stain: H\&E.

Fig (3): Group (II), a photomicrograph of dog liver showing in (A) and (B) binucleated cells and hypertrophy of the hepatocyte (straight arrow) and enlarged blood sinusoids contain hypertrophied kupffer's cells (curved arrow). Stain: H\&E.

Fig (4): Group (II), a photomicrograph of dog liver showing hypertrophy and vaccuolation of the hepatocytes (straight arrow) and congested blood sinusoids (curved arrow). Stain: H\&E. 

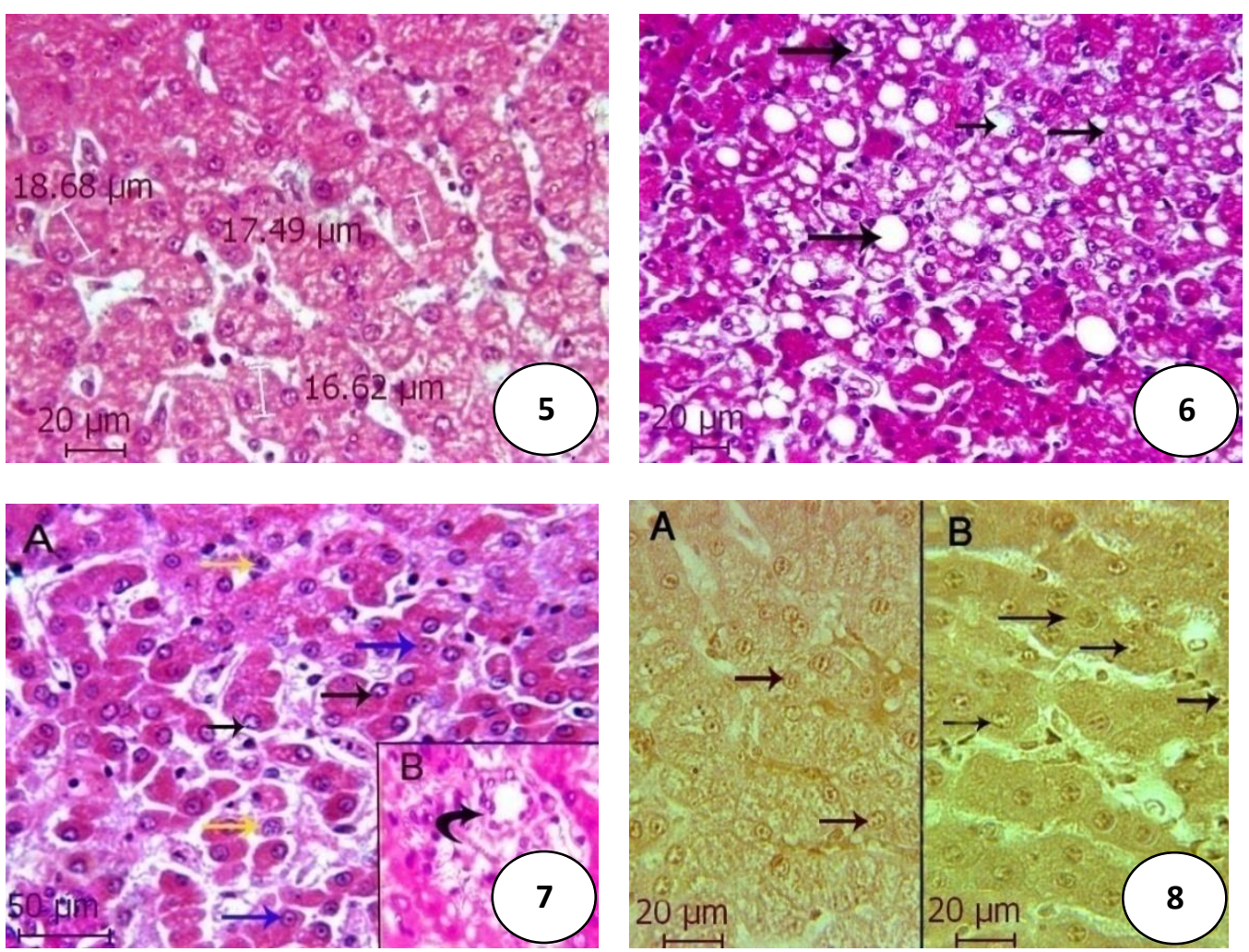

Fig (5): Group (II), a photomicrograph of dog liver showing the average size of the hypertrophied hepatocytes. Stain : H\&E.

Fig (6): Group (II), a photomicrograph of dog liver showing vaccuolation of the hepatocytes (straight arrow). Stain : H\&E.

Fig (7): Group (II), a photomicrograph of dog liver showing A- nuclei at different stages of nuclear division (straight arrow). B- Newly formed bile duct (curved arrow). Stain: H\&E.

Fig (8): A photomicrograph of dog liver showing the mitotic activity of the hepatocytes (straight arrow) in A- Group (II) B- Group (III). Stain: Heidenhain's iron haematoxylin. 

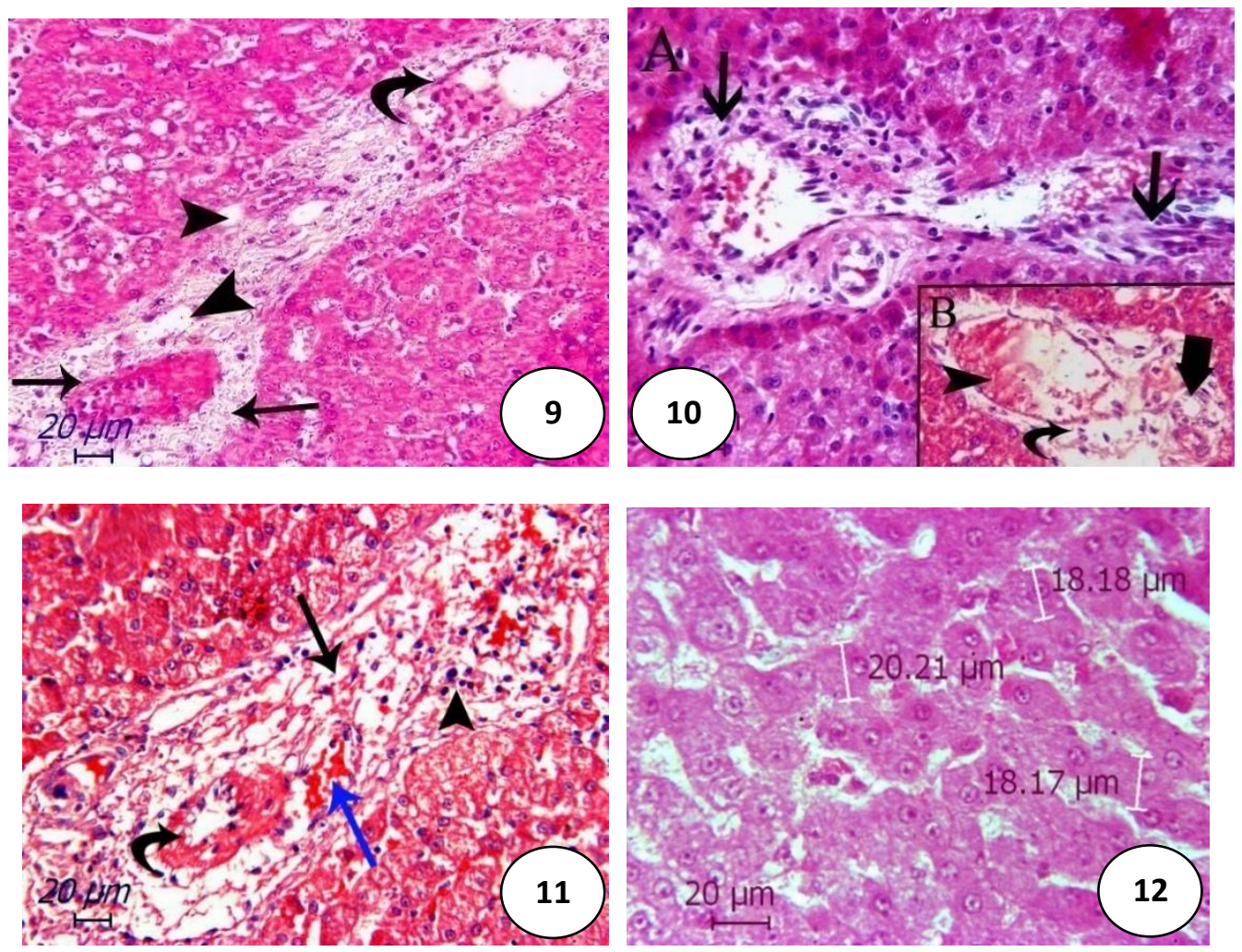

Fig (9): Group (II), a photomicrograph of dog liver showing hyalinization in the wall of the central vein which contain hemolyzed RBCs (straight arrow), edema (head arrow) and thrombosis (curved arrow). Stain: H\&E.

Fig (10): Group (II), a photomicrograph of dog liver showing A- proliferation of the fibroblasts and angioblasts, B- portal area contain congested hepatic artery (head arrow), edema (curved arrow) and newly formed bile duct (thick arrow). Stain : H\&E.

Fig (11): Group (II), a photomicrograph of dog liver showing thickening in the wall of the bile duct (curved arrow), edema (straight black arrow), newly formed blood capillaries (straight blue arrow) and proliferation of the fibroblasts and angioblasts (head arrow) in the portal area. Stain: H\&E.

Fig (12): Group (III), a photomicrograph of dog liver showing the size of the hypertrophied hepatocytes. Stain: H\&E. 

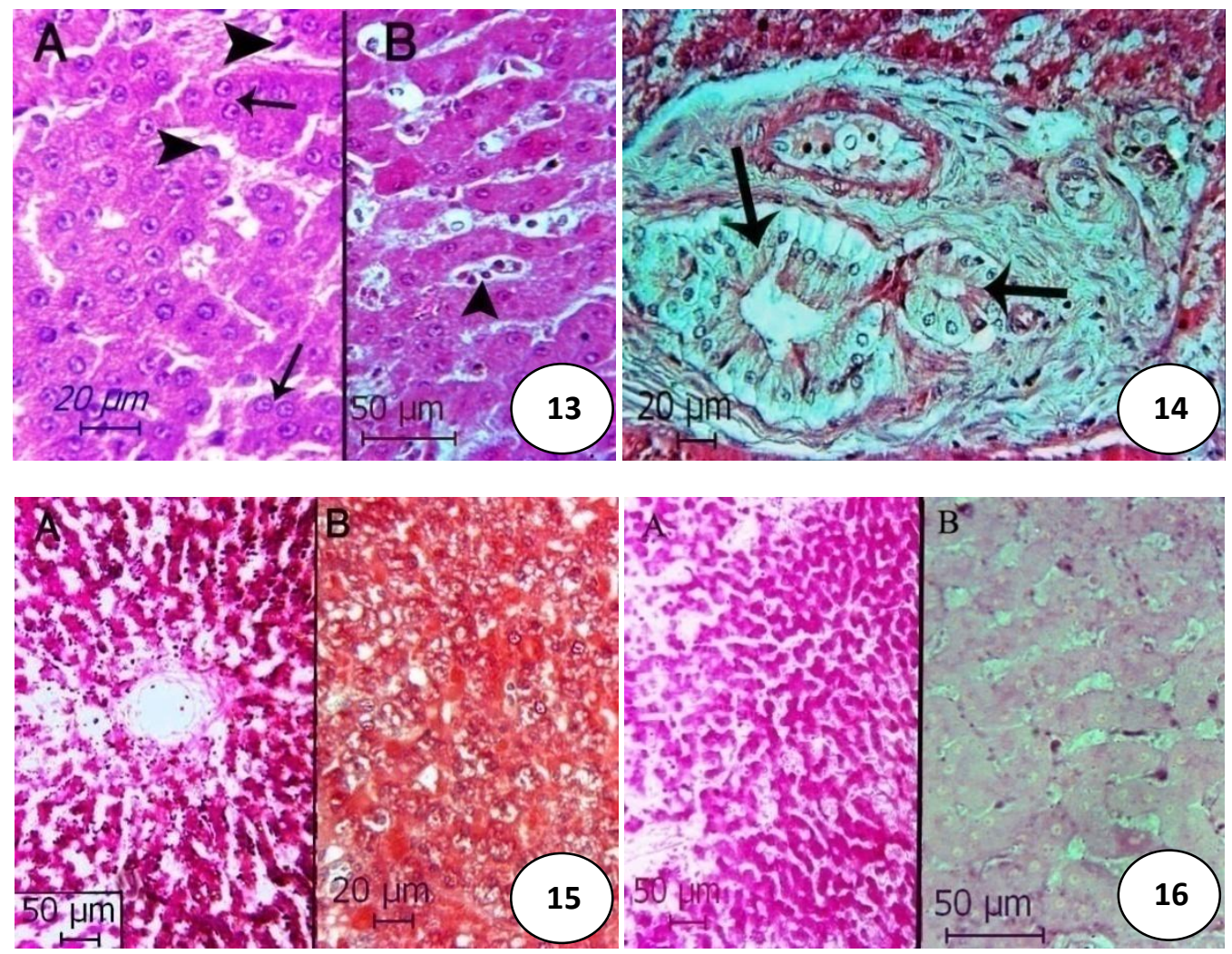

Fig (13): Group (III), in A\&B- a photomicrograph of dog liver showing binucleated cells and hypertrophy of the hepatocytes (straight arrow), hypertrophy and hyperplasia of the kupffer's cells (head arrow). Stain: H\&E.

Fig (14): Group (III), a photomicrograph of dog liver showing hypertrophy in the epithelial lining of the bile duct (straight arrow). Stain : H\&E.

Fig (15): Group (I), a photomicrograph of dog liver showing intensive positive reaction to A- (PAS) B- best's carmine. Stain: (PAS) stain and Best's carmine method.

Fig (16): A photomicrograph of dog liver showing A- moderate reaction to PAS in group (II) B- faint reaction to PAS in group (III). Stain: (PAS) stain. 

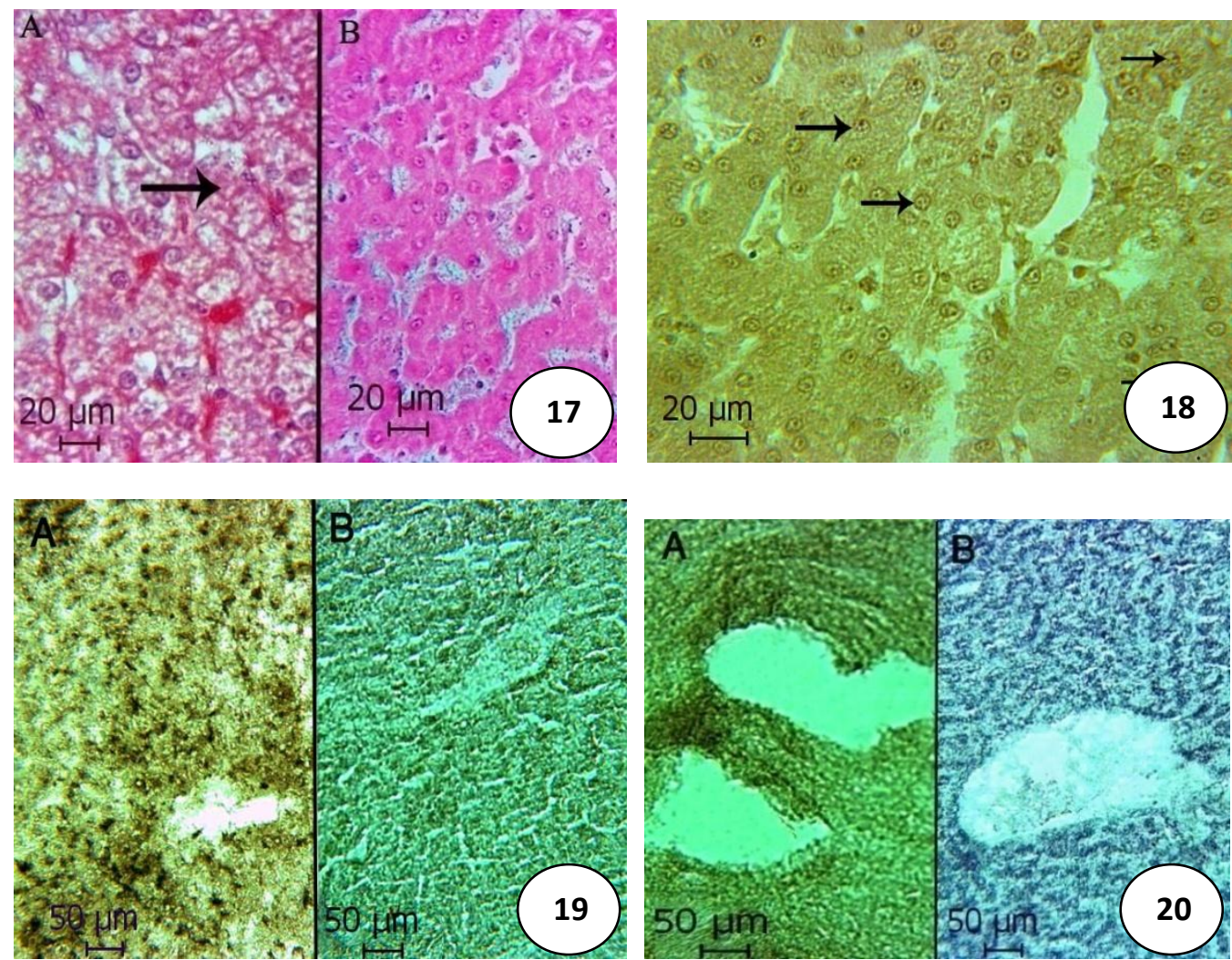

Fig (17): A photomicrograph of dog liver showing A- moderate reaction to Best's carmine stain in group (II) B- faint reaction in group (III). Stain: Best's carmine method.

Fig (18): Group (I), a photomicrograph of dog liver showing the mitotic activity of the hepatocytes (straight arrow). Stain: Heidenhain's iron haematoxylin stain.

Fig (19): Group (I), a photomicrograph of dog liver showing moderate reaction to A- acid phosphatase B- alkaline phosphatase in the hepatocytes. Stain: Gomori's lead method and calcium cobalt method.

Fig (20): Group (I), a photomicrograph of dog liver showing moderate reaction to AATPase B- SDH in the hepatocytes. Stain: Modified method and Nitro-blue tetrazolium (NBT) method. 

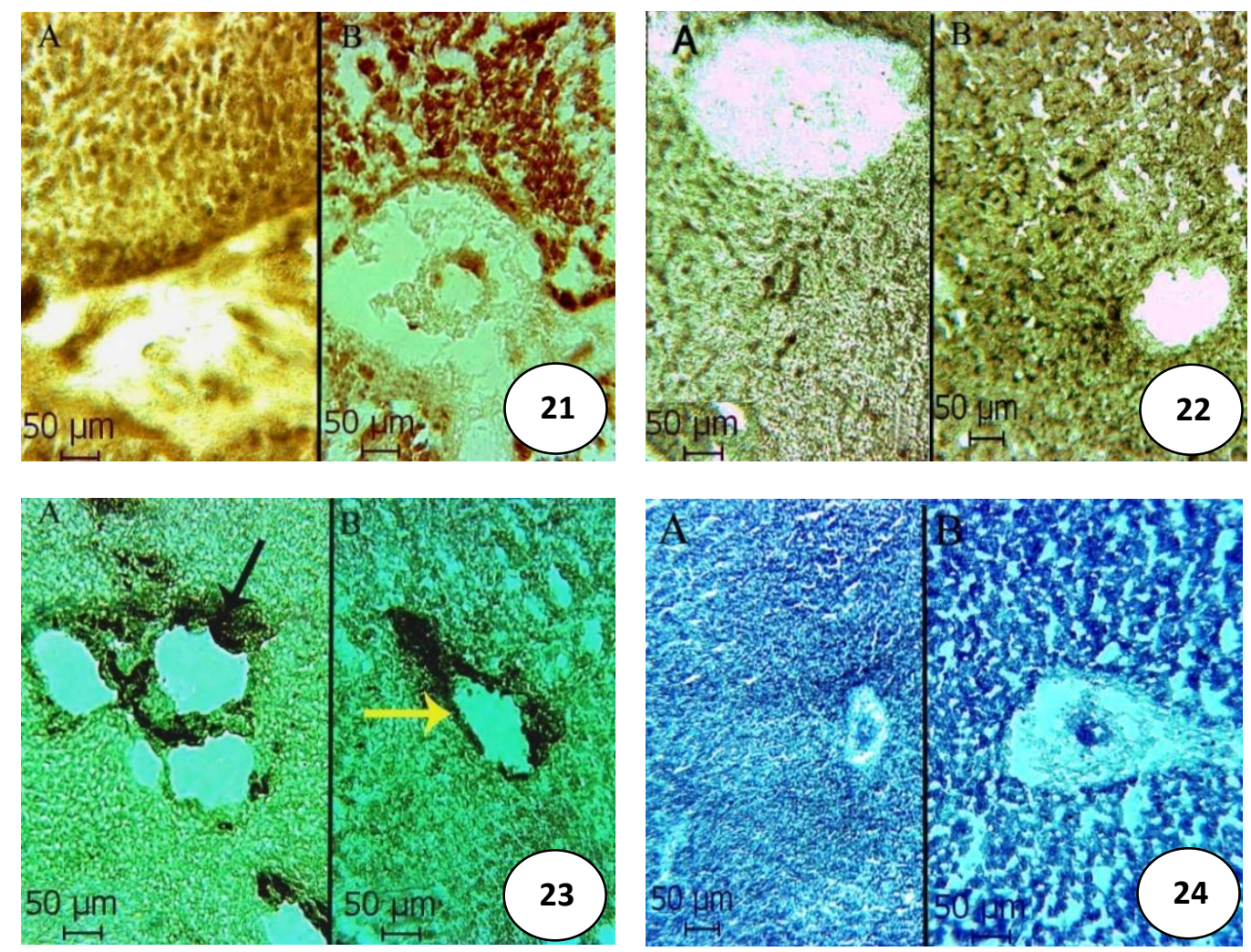

Fig (21): A photomicrograph of dog liver showing intensive positive reaction to acid phosphatase in A- group (II) and B- group (III). Stain: Gomori's lead method.

Fig (22): A photomicrograph of dog liver showing intensive positive reaction to alkaline phosphatase in A-group (II) and B-group (III). Stain: Calcium cobalt method.

Fig (23): A photomicrograph of dog liver showing intensive positive reaction to ATPase in A- group (II) and B- group (III). Stain: Modified method.

Fig (24): A photomicrograph of dog liver showing intensive positive reaction to in Agroup (II) and B- group (III). Stain: Nitro-blue tetrazolium (NBT) method. 